\title{
Incidence and Risk Factors of Falls and Fall-Related Injuries at the Medical and Surgical Wards of the Philippine General Hospital
}

\author{
Juanito S. Javier, ${ }^{1}$ Cynthia D. Ang-Muñoz, ${ }^{2}$ Lorna R. Abad, ${ }^{3}$ Mildred B. Campo, ${ }^{4}$ \\ Ruzanne M. Caro ${ }^{5}$ and Evangeline E. Rafael ${ }^{4}$ \\ ${ }^{1}$ Department of Orthopedics, College of Medicine and Philippine General Hospital, University of the Philippines Manila \\ 2Department of Rehabilitation Medicine, College of Medicine and Philippine General Hospital, University of the Philippines Manila \\ ${ }^{3}$ Department of Pediatrics, College of Medicine and Philippine General Hospital, University of the Philippines Manila \\ ${ }^{4}$ Division of Nursing Research and Development, Philippine General Hospital \\ ${ }^{5}$ Department of Otorhinolaryngology, College of Medicine and Philippine General Hospital, University of the Philippines Manila
}

\begin{abstract}
Objective. There is no published local data available on falls and fall-related injuries among hospitalized patients. This study aims to determine the incidence of falls, fall-related injuries and related risk factors at the surgical and medical wards of a tertiary government hospital in the Philippines.
\end{abstract}

Methods. This is a cross-sectional study using consecutive sampling of patients admitted to the medical and surgical wards of a tertiary government hospital from May 2014 to April 2015. Data collection included the patients' demographic data, diagnosis, medications, details on the fall, consequence of the fall, and risk factors for the fall.

Results. During the one-year period, 25,849 patients were admitted to the medical and surgical wards and only six patients, representing $0.02 \%$, were reported to have sustained a fall. No major injury occurred. The patients had varied neurologic and/or musculoskeletal disorders. Two patients fell from a wheelchair, while one fell from a bedside chair. One patient fell from the bed and one slipped on the floor. All patients had watchers/witnesses at the time of the fall.

Conclusion. The incidence of falls and fall-related injuries is low in a local tertiary government hospital. No serious injury resulted from the falls. Prevailing practices, local cultural expectations and under reporting may have affected the relatively low incidence rates of patient falls reported in this study.

Key Words: accident, falls, hospital, incidence, health care

Corresponding author: Juanito S. Javier, MD

Department of Orthopedics

Philippine General Hospital

University of the Philippines Manila

Taft Avenue, Ermita, Manila 1000 Philippines

Telephone: +6325548466

Email: juanitosjavier@yahoo.com

\section{Introduction}

For the past decade, there has been an increasing awareness of the impact of adverse events among hospitalized patients. An adverse event during hospitalization is defined as an injury caused by medical management rather than underlying disease, which prolongs hospitalization, produces a disability at the time of discharge, or both. ${ }^{1}$ A significant proportion of these events is due to fall.

Patients falling during hospital confinement is not a rare occurrence and has been reported in literature. Estimates for adverse events can go as high as $16.6 \%$ of hospitalized patients with falls comprising as much as $30 \%$ of all the adverse events. ${ }^{2,3}$ Wilson et al reported that $84 \%$ of adverse events in hospitalized patients were related to falls. ${ }^{4}$ Healey et al in 2007 reported that $32.3 \%$ of all patient safety incidents are patients falling. ${ }^{5}$

Falls can result, at best, to mild injuries or, at worst, lifethreatening condition, which may entail longer hospitalization, additional medications, and extra surgical procedures. In one report, $4 \%$ to $6 \%$ of patients who fell suffered severe injuries such as fracture or subdural hematoma. ${ }^{6}$ The cascading effect of an adverse event such as from a fall can lead to increased morbidity and even mortality.

These adverse consequences impose additional burden on an already stressed health care system. The National Health Service of Britain estimated an additional cost of 15 million British pounds per year is needed to cover for these injuries. ${ }^{5}$ The effect of these adverse events is not limited to expenses but to psychological consequences. The so-called 'post fall syndrome,' a psychological condition characterized by patient fear, diminished independence and self-esteem following falls and/or fall-related injuries, has been described. ${ }^{7}$ The impact includes loss of the patient's independence, psychological trauma, pain, disability, loss of trust on the health care system, and loss of productivity. It has effects not just on the patient or his family. Care providers likewise may fear blame and retribution through litigation and of loss of professional respect. ${ }^{8}$ Consequently, these may lead to depression, stress, shame, guilt and inadequacy. 
Krauss et al listed predictors of patient fall, namely: gait or balance impairment; lower extremity problem; confusion; use of sedatives/hypnotics; use of diabetes medications; activity level; and, increasing patient to nurse ratio. ${ }^{9}$ Several methods of identifying patients at high risk for fall have been described. Tools for risk assessment of individual patients have been proposed and used in order to mitigate the problem of falling. Different risk assessment such as the Morse Fall Scale (MFS) ${ }^{10}$ and the St. Thomas Risk Assessment Tool (STRATIFY) ${ }^{11}$ have been proposed. The STRATIFY scale was found to be the best tool for assessing the risk of fall by hospitalized adults. ${ }^{12}$ However, even this tool cannot be universally used. It has to be modified to suit the prevailing conditions and practices in a given locality. ${ }^{13}$ Thus, all the recommendations on this adverse event that are cited in foreign studies cannot be directly applied to our local setting. The search for local literature on the topic revealed no published study on falls of hospitalized patients. The local incidence of falls and the factors leading to falls are not known. A local study on falls was conducted on elderly persons in a nursing home facility for religious sisters and elderly patients who consulted at the Rehabilitation Medicine Out-patient Department of this study hospital. The participants were examined on cognitive function, balance and visual acuity and were interviewed every two months over a 10 -month period. The participants were asked if they have experienced a fall during the study period. As such, the study reported an incidence of $32 \%$ of the patients falling in the combined two groups during their 10 -month study period. ${ }^{14}$

This study is a first step in understanding this problem in our own hospital setting. Prevention of falls is the best way to address this problem. However, the occurrence of falls is not just dependent on the patient factors but also on the environmental factors such as the prevailing local health beliefs and practices and health care facility set-up.

\section{Objectives}

General Objective: To investigate the occurrence of falls and fall-related injuries at the medical and surgical wards of the Philippine General Hospital from May 2014 to April 2015.

\section{Specific Objectives:}

1. To determine the incidence of falls and fall-related injuries at the medical and surgical wards of the Philippine General Hospital over a one year period.

2. To determine the risk factors for falls at the medical and surgical wards of the Philippine General Hospital.

\section{Methods}

This is a cross-sectional study using consecutive sampling of patients who fell while admitted at all the Philippine General Hospital charity medical and surgical wards. The pediatric wards and neonatal units were excluded. The study was conducted over a one-year period from May 2014 to April 2015.

The study protocol was submitted to and approved by the University of the Philippines Manila Research Ethics Board (UPMREB). All investigators have no conflict of interest in this study.

A presentation of the study and its reporting mechanics was made to the ward head nurses prior to the study proper. A dedicated research assistant was tasked to put up reminders, mechanics and notices on the wards and made regular rounds in the different study areas. A fall was defined as an event in which a patient suddenly and involuntarily comes to rest on the floor with or without physical injury. Once a report of an incident of fall was received, an informed consent was obtained by the research assistant for inclusion into the study. Data collection included the patient's demographic characteristics, diagnosis, and medications; circumstances surrounding the incident; and potential risk factors for fall. The data collection form included a portion to be answered by the nurse on duty and the remaining portion of the form by the research assistant upon interview of the patient and/or relatives/witnesses.

Descriptive statistics such as frequency and percentage were computed for the different types of fall-related injuries and risk factors reported. Incidence was computed using the frequency of falls as the numerator and the total admissions in the included wards as the denominator. A sample size of 24 was estimated using the formula for trait or factor prevalence. No further statistical analysis was carried out once a very limited sample was obtained.

\section{Description of Study Hospital}

The study was conducted at the University of the Philippines-Philippine General Hospital (UP-PGH), a government-funded tertiary referral medical center and training hospital with over 1,000 beds for charity/non-paying patients. The typical patient comes from the low-income sector of the population. A standard ward in the UP-PGH consists of a single hall shared by many patients. A nurse's station is often located at the front end of the hall while comfort rooms are situated at the other end. Bedside commodes are not uniformly available in all the wards.

Per the hospital's admission policy, a watcher is required to stay with the patient during the entire duration of the hospital stay. This person, called a "bantay" in the local dialect, is often a relative, a friend or a person hired by the family. A small side table with or without seat is provided and the "bantay" would stay or sleep beside the patient's bed during the day, and sometimes, even under the bed at night. According to the Nursing Division of the hospital, the current nurse-to-patient ratio is 1:18. 
A review of the hospital's Measurement Analysis and Improvement (MAI) Nursing Services report for 2010-2014 revealed that of the total number of over 40,000 admissions per year, the number of reported patient falls in all the wards (inclusive of the pediatric units, neonatal intensive care units, pay wards and other areas in the hospital) ranged from 8 to 14 falls per year (Table 1$).{ }^{15}$

Table 1. Incidence of falls from 2010 to 2014 at the Philippine General Hospital (from Measurement Analysis and Improvement Nursing Services Reports) $)^{15}$

\begin{tabular}{cccc}
\hline Year & $\begin{array}{c}\text { Total No. of } \\
\text { Admission }\end{array}$ & $\begin{array}{c}\text { Incidents } \\
\text { of Fall }\end{array}$ & $\begin{array}{c}\text { Fall \% of Total } \\
\text { Admission }\end{array}$ \\
\hline 2010 & 46,066 & 8 & 0.02 \\
2011 & 46,327 & 12 & 0.02 \\
2012 & 41,262 & 8 & 0.02 \\
2013 & 44,980 & 13 & 0.03 \\
2014 & 45,505 & 14 & 0.03 \\
\hline
\end{tabular}

\section{Results}

A total of 25,849 patients were admitted to the included hospital units/wards over the 12-month period. Only six cases of fall were reported. No injury requiring any surgical or medical intervention resulted from the fall. The number of reported fall incidents falls short of the required sample size of 24, making inferential statistical analysis no longer feasible. The number of falls translates to a rate of $0.02 \%$ incidence of patient falls.

The patients' profile is presented in Table 2. There were three children (one male and two females) and three adults (two males and one female). The youngest patient was seven years old while the oldest was 55 years old. The mean age among the pediatric patients was 7.34 years while the adult patients had a mean age of 47.34 years. Three were neurological cases, namely, cerebrovascular disease, spinal cord injury and stroke in the young. One adult patient had chemical burns while one pediatric patient had hypertrophic scars secondary to flame burn. The other pediatric patient was a case of congenital below knee amputation. All patients were already in their rehabilitation stage and undergoing more mobility activities. All were mobile with two using wheelchair while the other four using gait aids. Four of the six incidents were reported late in the afternoon. One fell during the morning while another fell at night. Two patients fell while transferring from a wheelchair in the ward. One fell from a bedside chair. Two patients fell from the bed while one slipped on the floor in the ward. All but one incident occurred in the main ward while only one fall incident happened in the toilet.

One of the patients was under carbamazepine medication. All except one were alert during the time of fall. One patient was asleep when he fell from bed. All instances of fall had witnesses. Only one fall incident was witnessed by someone other than his own watcher. This patient's watcher requested a fellow watcher to keep an eye on the patient at the time of the fall (Table 2).

\section{Discussion}

The incidence rate of $0.02 \%$ in this study is small compared to the figures reported in other countries. Underreporting cannot be discounted as a reason for the low number of reported falls.

Figures reported in published literature were mainly from developed countries where the hospital environment and medical facilities and practices are different from those evident in the local setting. The general set-up in the study hospital for both the surgical and medical wards is such that all the beds are situated side by side arranged in at least two long rows across one big hall. Often only those patients requiring isolation are confined in a single occupancy room. The ratio of patient to nurse is very low. A 24/7 watcher who is either a relative or friend supplements the nursing care needs. The watcher or "bantay" stays beside the patient. While it is a hospital policy for admission to the charity wards at the UP-PGH that each patient should have one 'bantay,' it is customary and culturally expected that someone will be available at the side of the patient while confined in the hospital. This is a manifestation of how culture affects every aspect of people's lives including health care. ${ }^{16}$ The 'bantay' is expected to assist the patient in performing all the activities while confined in the ward, including self-care skills, mobility out of bed, and going to and from the toilet if the patient has bathroom privileges.

Table 2. List of hospitalized patients who fell and related data

\begin{tabular}{|c|c|c|c|c|c|c|c|c|}
\hline & $\begin{array}{c}\text { Age / } \\
\text { Sex }\end{array}$ & Diagnosis & $\begin{array}{c}\text { Time of fall } \\
\text { (shift) }\end{array}$ & $\begin{array}{c}\text { Watcher } \\
\text { during fall }\end{array}$ & $\begin{array}{c}\text { Level of } \\
\text { consciousness } \\
\end{array}$ & $\begin{array}{c}\text { Last medication } \\
\text { taken nearest to fall }\end{array}$ & Manner of fall & Witness \\
\hline 1 & $49 / \mathrm{M}$ & $\begin{array}{l}\text { Cerebrovascular injury, } \\
\text { Hypertension }\end{array}$ & $\begin{array}{l}\text { PM - reported } \\
\text { within shift }\end{array}$ & Wife & Alert & Atorvastatin & $\begin{array}{l}\text { Bedside chair } \\
\text { (in ward) }\end{array}$ & Own watcher \\
\hline 2 & $7 / \mathrm{F}$ & $\begin{array}{l}\text { Hypertrophic scar } \\
\text { secondary to flame burn }\end{array}$ & $\begin{array}{l}\text { PM - reported } \\
\text { within shift }\end{array}$ & $\begin{array}{l}\text { Watcher of } \\
\text { room mate }\end{array}$ & Alert & None & Bed & $\begin{array}{l}\text { Watcher of } \\
\text { neighboring bed }\end{array}$ \\
\hline 3 & $8 / \mathrm{F}$ & Stroke in the young & $\begin{array}{l}\text { PM - reported } \\
\text { within shift }\end{array}$ & $\begin{array}{l}\text { Grand- } \\
\text { mother }\end{array}$ & Alert & Carbamazepine & $\begin{array}{l}\text { Wheelchair } \\
\text { (in ward) }\end{array}$ & $\begin{array}{l}\text { Watcher of } \\
\text { neighboring patients }\end{array}$ \\
\hline 4 & $55 / \mathrm{F}$ & Chemical burns & $\begin{array}{l}\text { PM - reported } \\
\text { within shift }\end{array}$ & Mother & Alert & none & $\begin{array}{l}\text { Slipped on floor in } \\
\text { ward }\end{array}$ & Own watcher \\
\hline 5 & $38 / \mathrm{M}$ & Spinal cord injury & $\begin{array}{l}\text { AM - reported } \\
\text { within shift }\end{array}$ & Nephew & Alert & Ascorbic acid & $\begin{array}{l}\text { Bumped on wheelchair } \\
\text { edge (in toilet) }\end{array}$ & Own watcher \\
\hline 6 & $7 / \mathrm{M}$ & $\begin{array}{l}\text { Below knee amputation - } \\
\text { congenital }\end{array}$ & $\begin{array}{l}\text { Night Shift - } \\
\text { reported after shift }\end{array}$ & Mother & Asleep & None & $\begin{array}{l}\text { Rolled from bed while } \\
\text { sleeping }\end{array}$ & Own watcher \\
\hline
\end{tabular}


The presence of the 'bantay' that is not seen in other countries could greatly affect the incidence rate of falls. The 'bantay' is there to give the patient what he needs and frees the patient from reaching for them. The 'bantay' is also there to accompany the patient to the toilet. Often the toilet is situated at the far end of the ward and this may discourage the patient from getting down from bed. Instead, he would use a urinal or a 'bedpan'. A bedside commode however is not readily available. For bed-bound patients who are more debilitated, caregivers would use disposal diapers and/or, upon medical advice, indwelling or condom catheters. The impact of the 'bantay' system on the delivery of health care, in particular on patient fall incidence is a topic worth studying.

Another prevailing local health belief that may have an effect on the incidence is the fear of "binat," (relapse). It is a prevailing cultural belief that any exertion during the recovery phase of any illness can lead to a relapse. Naturally, the patient would rather stay in bed instead of mobilizing whenever this has already been advised. This practice may be further reinforced by the caregivers.

The reported fall incidents in this study involved patients who were all already in their rehabilitation stage and this concurs with the finding of Teasel et al that patients in rehabilitation units are at high risk. ${ }^{17}$ Intake of medications such as benzodiazepines or sedative hypnotic drugs were implicated as contributory factors in some studies. ${ }^{18}$ One of the patients in this study was taking carbamazepine. Some reported side effects of this drug are loss of coordination, drowsiness or dizziness. Other factors such as state of confusion, ${ }^{19}$ comorbidities, and impaired functional status ${ }^{20}$ are considered contributory but none of our cases validated these assertions.

The other possible reason of the low incidence is the underreporting of cases. This is an inherent weakness of studies relying on self-reporting. The fear of negative repercussions on the part of the nursing staff and also on the 'bantay' or other witness acts as a deterrent to reporting. Often the falls do not result in visible injury and thus it is not given due notice.

\section{Conclusion and Recommendations}

The incidence of falls obtained in a local tertiary government hospital is markedly low compared to reported rates in the literature. In most likelihood, both the difference in the local hospital setting and practices plus underreporting contributed to the low incidence. This initial attempt to understand the nature of patient falls in our local setting highlights the need to study these factors affecting the reporting process. The impact on patient fall incidence rates by the presence of a $24 / 7$ 'bantay' (watcher), prevailing concepts of 'binat' (relapse) and other practices require further investigation. Strategies to overcome underreporting need to be designed. We may need to consider and monitor other indirect indicators of falls such as reported injuries in order to get a better grasp of the extent of falls in hospitalized patients. A review on the setup of the ward, in particular provisions for safe mobility to and from the patient's bed to the ward toilet, and other environmental factors that can increase the risk of falls should also be considered. Understanding these factors is essential to the future development of a risk stratification and prevention program for all patients who are and will be admitted in the hospital, including patients from other charity wards and pay floors. Patients in diagnostic units and treatment facilities including the operating rooms, recovery rooms, and the emergency room should also be included in future studies.

\section{References}

1. Brennan TA, Leape LL, Laird NM, et al. Incidence of adverse events and negligence in hospitalized patients. Results of the Harvard Medical Practice Study I. N Engl J Med. 1991; 324(6):370-6.

2. Thomas EJ, Studdert DM, Burstin HR, et al. Incidence and types of adverse events and negligent care in Utah and Colorado. Med Care. 2000; 38(3):261-71.

3. Wilson RM, Runciman WB, Gibberd RW, Harrison BT, Newby L, Hamilton JD. The quality in Australian health care study. Med J Aust. 1995; 163(9):458-71.

4. Wilson EB. Preventing patient falls. AACN Clin Issues. 1998; 9(1):100-8.

5. Healey F, Scobie S. The third report from the Patient Safety Observatory. Slips, trips and falls in hospital. The National Patient Safety Agency (NPSA), 2007.

6. Hitcho EB, Krauss MJ, Birge S, et al. Characteristics and circumstances of falls in a hospital setting: a prospective analysis. J Gen Intern Med. 2004; 19(7):732-9.

7. Murphy J, Isaacs B. The post-fall syndrome. A study of 36 elderly patients. Gerontology. 1982; 28(4):265-70.

8. Asden P, Corrigan JM, Wocott J. (ed.). Patient Safety - Achieving a new standard for care. Washington, DC: Institute of Medicine, The National Academies Press; 2004. p. 32.

9. Krauss MJ, Evanoff B, Hitcho E, et al. A case-control study of patient, medication, and care-related risk factors for inpatient falls. J Gen Intern Med. 2005; 20(2):116-22.

10. Morse JM. Preventing patient falls, $2^{\text {nd }}$ ed. New York: Springer Publishing Co; 2009. pp. 52 - 53.

11. Oliver D, Britton M, Seed P, Martin FC, Hopper AH. Development and evaluation of evidence based risk assessment tool (STRATIFY) to predict which elderly inpatients will fall: case-control and cohort studies. BMJ.1997; 315(7115):1049-53.

12. Aranda-Gallardo M, Morales-Asencio JM, Canca-Sanchez JC, et al. Instruments for assessing the risk of falls in acute hospitalized patients: a systematic review and meta-analysis. BMC Health Serv Res. 2013; 13:122.

13. Oliver, D, Papaioannou, A, Giangregorio L, Thabane L, Reizgys K, Foster G. A systematic review and meta-analysis of studies using the STRATIFY tool for prediction of falls in hospital patients: how well does it work? Age Ageing. 2008; 37(6):621-7.

14. Evangelista TJ, Guevarra DG. The incidence and identification of risk factors for falls among Filipino elderly persons in a nursing home facility and at the Rehabilitation Medicine Out-Patient Department of the Philippine General Hospital. Acta Med Philipp. 2010; 44(2):38-44.

15. Measure and Analysis Improvement Reports, Philippine General Hospital, 2010 - 2014.

16. Tan-Alora A. Philippine culture and bioethics. In: Ren-Zong Qiu, ed. Bioethics: Asian perspectives - a quest for moral diversity. SpringerScience+Business Media, B.V; 2004. pp. 71-82. 
17. Teasell R, McRae M, Foley N, Bhardwaj A. The incidence and consequences of falls in stroke patients during inpatient rehabilitation: factors associated with high risk. Arch Phys Med Rehabil. 2002; 83(3):329-33.

18. Tinetti ME, Speechley M, Ginter SF. Risk factors for falls among elderly persons living in the community. N Engl J Med. 1988; 319(26):1701-7.
19. Hendrich AL, Bender PS, Nyhuis A. Validation of the Hendrich II fall risk model: a large concurrent case/control study of hospitalized patients. Appl Nurs Res. 2003;16(1):9-21.

20. Rothschild JM, Bates DW, Leape LL. Preventable medical injuries in older patients. Arch Intern Med. 2000; 160(18):2717-28.

\section{Acta Medica Philippina \\ THE NATIONAL HEALTH SCIENCE JOURNAE

\section{Acta is now accepting} membership

\section{Privileges of members:}

- Allows you to submit articles for possible publication

- Have access to all the articles in the website (archives included) which can be downloaded and printed in pdf format

- Advertise your products/services in the available spaces of the website (for approval of the Editor-in-chief)

For details, please visit our website at www.actamedicaphilippina.com.ph or e-mail us at businessmanager@actamedicaphilippina.com.ph for any questions or queries. 